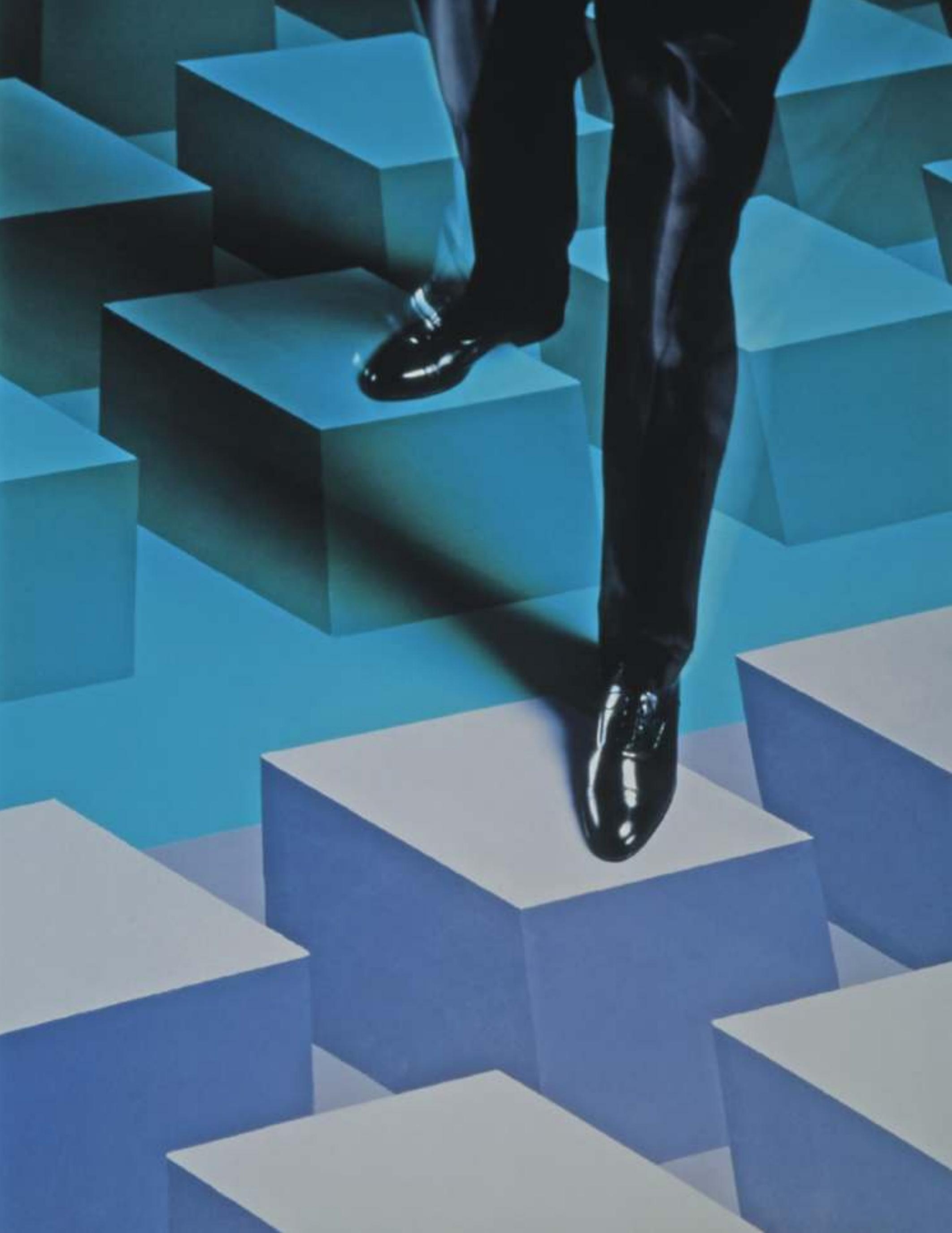




\section{Almacenes Éxito: Logística de clase mundial}

ESUMEN

\author{
Almacenes Éxito S.A. es \\ la mayor cadena de \\ abastecimiento de \\ productos al por menor \\ de Colombia. Este \\ artículo, realizado a \\ partir de la \\ videoconferencia \\ concedida a la EAN por \\ su gerente de logística, \\ describe las claves del \\ éxito de su vasta red de \\ distribución y su afinidad \\ con la misión \\ institucional: la \\ prestación de servicio al \\ cliente.
}

Por:

Rafael Pérez Uribe ${ }^{1}$

\begin{abstract}
A Imacenes Éxito S.A. es la primera compañía de ventas al por menor en Colombia, con ingresos por ese concepto superiores a los tres billones de pesos anuales. Esta cifra duplica ampliamente a la segunda compañía del mercado minorista en el país. De ese volumen de mercancía, alrededor del $85 \%$ pasa a través de su propia red de distribución, pues tan sólo un $15 \%$ de los proveedores entregan su mercancía directamente en el punto de venta. Este alto volumen de carga involucra al día unos 500 despachos de camiones, que movilizan aproximadamente unas tres mil toneladas a ciudades tan distantes como Apartadó e Ipiales.
\end{abstract}

El eje de esta vasta red logística son los grandes centros de distribución de Bogotá y Envigado. A estos se suman las plataformas de reexpedición de Barranquilla, Pereira y Bucaramanga, y la red de transporte. En Envigado, se acaba de inaugurar el centro de distribución más grande de cualquier cadena del país, el Centro de Distribución Las Vegas, en pleno corazón del área metropolitana, con un área cubierta de unos $55.000 \mathrm{~m}^{2}$; por su parte el centro de distribución de Bogotá tiene $45.000 \mathrm{~m}^{2}$.

Para esta organización es claro que en el mundo la logística tiene lugar entre proveedores y detallistas, y entre

\footnotetext{
1 Por Rafael Pérez Uribe, candidato a doctor Universidad Antonio de Nebrija (España). M.Sc Universidad de Québec. Profesor asociado Universidad EAN. Bogotá. La información de este artículo proviene de la entrevista en videoconferencia concedida desde Medellín por el doctor Luis Alberto Gil, Gerente de Logística de Almacenes Éxito.
} 
proveedores y clientes. En un concepto de cadenade abastecimiento es tan importante la logística intema (dentro del concepto de distribución de almacenes) como la logística con los proveedores. Se trata, por tanto, de un planteamiento que toma en cuenta todas las partes interesadas y las mejores prácticas posibles.

Almacenes Éxito emplea en un $94 \%$ de las órdenes decompra con los proveedores de mercancíala tecnología BTB (business to business), sistema de publicación para envío de pedidos; sólo con un $6 \%$ de los proveedores (proveedores pequeños de frutas y verduras) se utilizan sistemas convencionales para realizar pedidos.

Para una compañía grande como Almacenes Éxito, la logística es un proceso estratégico, porque el principal servicio que ofrece a sus clientes es «que nunca falte el producto en el punto de venta y que ese producto sea de la mejor calidad y al menor costo posible». Desde este punto de vista el logístico es un proceso fundamental, pues de su gestión depende la provisión de productos en sus puntos de venta.

Por su incidencia en los costos finales de los productos, Almacenes Éxito maneja su plan logístico en términos de gestión de productividad con el fin de controlar y reducir los costos a los límites establecidos. Para Almacenes Éxito todo plan estratégico está antecedido de un estudio del plan logístico. Así sucede, por ejemplo, cuando se toma la decisión de expandirse a otras ciudades e incursionar en nuevos negocios. Abrir negocios en ciudades tan alejadas como Apartadó es un reto para la compañía en dos sentidos: primero se trata de atraer a los compradores potenciales, segundo de hacer llegar los productos hasta esa localidad a un precio razonable.

La logística es disponibilidad y oportunidad. En esencia, Almacenes Éxito ha ido construyendo una red logística que tiene como elemento fundamental el sitio y el tiempo en que los artículos se entregan. Para cada uno de los almacenes, en cada ciudad y por cada tipo de mercancía, existe una programación de entrega que señala hora y frecuencia.

\section{Abstract}

Almacenes Éxito S.A. is the largest shop of retail products in Colombia.

This paper describes the key factors of its large net of logistics and its affinity with the

institutional mission: the service and satisfaction of the client. The information here provided comes from a teleconference conceded by the chief logistics officer of the company to the EAN.

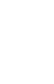

to

.


Se entregan productos frescos como frutas $y$ verduras y frescos industriales, en ciudades como Bogotá, Medellín y Cali todos los días. Cada almacén tiene una hora exacta de recepción de mercancía, los sitios, las frecuencias. Por ejemplo el centro de distribución Las Vegas, tiene ciento ocho muelles para recibo de mercancía, se sabe qué proveedores van a llegar y a qué hora. A la hora de evaluar el servicio, hay indicadores claves, por ejemplo el compromiso de entregar a los puntos de venta en días y horas específicos. También se tienen en cuenta los resultados que arroja semestralmente la encuesta de servicio en los puntos de venta que evalúan, entre otros aspectos, el servicio de cada conductor.

En logística, se debe estar atento a qué productos y servicios conviene tercerear o no. En Colombia existe un desarrollo importante que permite contar con operadores de un excelente nivel de servicio. El transporte para Almacenes Éxito maneja múltiples negocios: productos frescos, congelados, ropa, alimentos, mercancía general, transporte de pescado fresco que se importa vía aérea. Por ello se buscan empresas reconocidas por su calidad de servicio, con conductores que posean toda la formación y la preparación de servicio al cliente.

Para la selección de estos transportadores, se tienen en cuenta características cualitativas y cuantitativas: los vehículos, el modelo, el mantenimiento, que tengan adecuaciones acordes al tipo de transporte (alimentos, ropa, refrigerados, etc.).

La gestión de proveedores de mercancía desde el punto de vista logístico posee las mejores prácticas que la logística en el mundo ha venido desarrollando las prácticas SDL, que conllevan esquemas de colaboración. A su vez se ha desarrollado toda una tecnología vía e-mail para confirmación de despachos, confirmación de recibos, etc., con lo cual se facilita la organización de la red de distribución.

Dependiendo de dónde tiene el proveedor sus instalaciones o centros de distribución se acuerda cual sería la mejor manera para la entrega de la mercancía. Se sigue el concepto de cadena de abastecimiento para que se utilice la red propia de Almacenes Éxito S.A., como una red común para ellos.

El servicio de empleados logísticos se desarrolla internamente pero también se han delegado algunas funciones a empresas de outsourcing. Hay proveedores que hacen maquila o conformación de productos, preparan etiquetas, paquetes de mercados básicos o anchetas para los grandes eventos del calendario comercial del país. En estos casos se acude a terceros expertos en preparación de embalajes.

En el tema de compras se puede hablar de dos aspectos: el de la negociación y el de reabastecimiento. El primero lo gerencia el área comercial, que administra el negocio y responden por la labor del contacto con el proveedor, de negociar condiciones, los precios y los eventos comerciales. La labor de reabastecimiento esta a cargo directamente del área de logística, bajo modelos de pronósticos de demanda, de cálculos de pedidos y agendas programadas con los proveedores para realizar pedidos con la frecuencia debida. En productos de baja rotación como prendas, los pedidos se hacen cada quince días o cada semana; en cuanto a productos frescos, los pedidos se hacen todos los días.

Uno de los grandes retos que tiene esta gran empresa es el manejo de los inventarios por varias razones: 
Primero, el inventario representa la mercancía que el cliente busca y el principal elemento de servicio para el consumidor es que exista el producto que requiere; nada más frustrante para un consumidor que vaya a un punto de venta y no encuentre lo que necesita; segundo, el exceso de productos es muy oneroso; la inmovilización de mercancías genera averías, recargo de trabajo y gastos adicionales.

El indicador de rotación de inventarios, la cantidad que se tiene en físico y el indicador de agotados frente al consumidor son tres indicadores fundamentales para el negocio. A través de ellos se busca garantizar que los almacenes ofrezcan siempre los productos que busca el cliente que encuentre rápido producto frescos. Este sistema poscuenta con dos herramientas fundamentales:

- El manejo de un modelo de pronósticos que analiza la historia de períodos anteriores y las expectativas de hoy y los cambios industriales de la compañía en marketing, calcularon el fin de calcular las cantidades solicitadas.

- La selección adecuada de los proveedores con la definición clara de las frecuencias, sitios de entrega y los volúmenes mínimos requeridos.

En un negocio como este hay algunos sistemas básicos de información.

- Un sistema básico de información para comunicarse con los proveedores, base del sistema BTB, que permite que se envíen los pedidos electrónicamente a los proveedores y que ellos avisen cuándo y cuánto despachan y cuánto se recibió realmente.

- Sistemas de información para el cálculo de los pronósticos y la producción de los pedidos. Es el modelo E3, un sistema de categoría mundial que se encarga de pronosticar y ordenar pedidos.

- Un software de gerencia logística, usado para manejar las operaciones en el centro de distribución, que permite recibir la mercancía a los proveedores, evacuarla hacia las áreas de almacenamiento, almacenarlas, despacharlas y manejar todo el inventario del centro de distribución. Este software Ilamado WMS - Warehouse Management System- es un sistema de manejo de bodegas, un paquete de software elaborado por casas mundiales que reúnen las mejores prácticas para administración de los centros de distribución.

A esto se suma el tema del resurtido, clave en el ambiente logístico. Hoy se identifica como «sistema ROTAR», que nació como un proyecto y quedó como distintivo del modelo de reabastecimiento. Todos los días para las ventas en los diferentes puntos, la registradora opera como un terminal apoyado por sistemas computacionales. En el sistema de cada almacén está el inventario de todos sus artículos y con cada operación de venta se va restando a la existencia. Al final del día, el sistema de información hace el juego de inventarios y dice con lo que empezó y con lo que terminó de inventario.

La información de cada almacén viaja por la noche al sistema central, donde el modelo de pronósticos y demandas, con base en el comportamiento del día y con base en las variables de inventarios y logística: tiempo de entrega, frecuencia y tamaños de entrega, calcula las necesidades de cada tienda por artículo en unidades. Esa información sale al equipo de reabastecedores, que le dan el visto bueno en forma global, de acuerdo con comportamientos atípicos o situaciones nuevas que se puedan presentar. En ese momento se genera el pedido, el cual puede 
ser: un artículo que está en un centro de distribución para que éste despache o un proveedor, si es bajo la modalidad de entregay venta.

Durante el día se vende, en la noche se transmite la información. Ahí mismo, el sistema de reabastecimiento y de pronósticos calcula el nuevo pedido al proveedor o al centro de distribución. Al día siguiente empieza el proceso de reabastecimiento. El recibo de proveedores funciona desde las 4:00 a.m. Algunos productos llegan cada día, otros, de más lenta rotación, como la ropa o mercancía general se reciben con menos periodicidad.

En Almacenes Éxito la logística se encuentra en un nivel jerárquico similar al de otras gerencias corporativas. Su relación con éstas es total, ya que la logística es una función que tiene que ver con todas ellas, principalmente, con la disponibilidad de producto. A grandes rasgos, se puede describir de la siguiente manera: el área comercial se encarga de la negociación, de proveedores, productos, precios, condiciones y del plan comercial de la compañía. La logística conoce todos esos elementos y se encarga del reabastecimiento de los centros de distribución y de los puntos de venta.

La logística trabaja en coordinación con el departamento de ventas. Con el área de operaciones coordina en los puntos de venta, la logística de llegada del producto; coordinar con cada punto de venta la hora apropiada de llegada de mercancías, en qué contenedores, en qué tipo de vehículos, etc. Con informática se establecen lo concerniente a los bloques de sistemas de información. Dicho manejo de información está orientado a la toma de decisiones.

Una de las claves de esta organización es que tiene una estructura claramente definida, en lo que concierne a sus niveles jerárquicos y los de decisión. Esto facilita la operación.
En el caso de logística, en el ámbito corporativo, se propone la estrategia, se definen los proyectos, los programas, los indicadores y se delega su ejecución y evaluación a los centros de distribución.

Sin embargo, por más planeación y programación, se presentan situaciones especiales o coyunturales todos los días en Bogotá, Medellín, Cali o Barranquilla que no se pueden resolver desde la Corporación. Para esto está la gente en cada zona, con suficientes herramientas e indicadores, y empoderada para actuar en caso de que así lo amerite.

La empresa ha sido destacada en el medio por la formación, el entrenamiento y la motivación para que la gente en los centros de distribución sienta al almacén y al consumidor como propios. La labor de logística consiste en que esa persona en el centro de distribución no sienta que simplemente está despachando mercancía, sino que está contribuyendo con la satisfacción del cliente.

Los conductores, a pesar de no estar vinculados directamente, reciben un proceso de formación y motivación igual al de todos los empleados, de tal manera que esas personas sean excelentes en el servicio a los clientes tanto en el punto de venta como cuando entregan a domicilio.

Almacenes Éxito S.A. (Ley, Pomona y Éxito), es un ejemplo de cadena de almacenes con talento Colombiano, cercana a las mejores del mundo en el tema logístico. Cuenta con 31 almacenes EXITO, 55 almacenes Ley, 10 supermercados POMONA y 2 tiendas Q'precios repartidos en 34 municipios colombianos, que conjuntamente sobrepasan los $330 \mathrm{mil} \mathrm{m}^{2}$ de área de ventas, generan cerca de 37 mil empleos entre directos e indirectos. Por sus almacenes pasan cada año más de 140 millones de personas. 